\title{
Nestling birds put their best flange forward
}

\author{
Matthew B. Dugas \\ M. B. Dugas (mdugas@ou.edu),Dept.of Zool., Univ. of Oklahoma, 730 Van Vleet Oval, Norman, Oklahoma, USA.
}

\begin{abstract}
The offspring of caring parents may evolve specialized traits uniquely adaptive during their dependence on parental care. For example, the mouths of passerine nestlings are often bordered by enlarged and colorful rictal flanges expressed only during the nestling period. Although these traits are commonly hypothesized to act as visual signals during begging, noncommunication functions for the specialized mouth have been proposed as well. To test the hypothesis that nestling flange colors have evolved largely or exclusively as visual signals, I compared the reflectance of flange tissue that would be visible to parents during begging to that of flange tissue not exposed during begging in nestling house sparrows Passer domesticus and cliff swallows Petrochelidon pyrrhonota. Specifically, I tested the prediction that both condition-dependent color parameters and those associated with visual conspicuousness would be expressed more intensely in tissue displayed during begging. Consistent with this prediction, flange tissue exposed during begging was brighter (reflected more total light), more UV-rich, and had more intense carotenoid-based coloration than hidden tissue. These differences do not exclude a non-signaling function for flanges, but are consistent with the hypothesis that flange colors have evolved as visual signals.
\end{abstract}

Parents often provide care to their young (Clutton-Brock 1991) which, in turn, evolve diverse behavioral (Kaptein et al. 2005), chemical (den Boer and Duchateau 2006), acoustic (Bell 2007) and morphological (Lyon et al. 1994, Jourdie et al. 2004) traits that encourage parental investment. Such offspring begging has been most extensively studied in altricial birds (reviewed in Wright and Leonard 2002). While dependent young birds may express specialized plumage (Lyon et al. 1994, Galván et al. 2008) and skin colors (Jourdie et al. 2004, Bize et al. 2006), the most common and striking visual component of the begging display is typically the nestling mouth (Swynnerton 1916, Kilner and Davies 1998), which is necessarily and prominently presented to parents when nestlings solicit and accept food deliveries.

The mouths of altricial nestlings differ morphologically from those of their parents, suggesting divergent adaptive functions. Enlarged rictal flanges commonly border the nestling's open mouth (Fig. 1), and both the flanges and the interior of the mouth are often elaborately colored (Ficken 1965, Clark 1969). Because flanges and mouth colors are expressed only while nestlings rely on their parents (Clark 1969) and are displayed during begging, these have been hypothesized to increase offspring fitness by increasing their receipt of parental care. Specifically, these morphological traits are commonly thought to have evolved in the context of visual communication between parents and offspring (Swynnerton 1916, Kilner and Davies 1998).

Various potential functions for these visual signals have been proposed. Flange and palate colors have been hypothesized to increase the detectability of nestlings in the often-restricted light environment at a nest (Ingram 1920, Kilner and Davies 1998, Avilés et al. 2008). Consistent with this hypothesis, comparative studies reveal that the flanges of nestlings reared in relatively dark places (e.g. cavities) reflect more total light (which probably mediates detectability, Osorio et al. 1999) than those of birds occupying more well-lit nests (Hunt et al. 2003, Avilés et al. 2008). A second hypothesis suggests that nestling mouth colors signal not only the presence and position of a nestling, but also features of its individual state (e.g. hunger: Kilner 1997, temperature: Clotfelter et al. 2003, or immune status: Saino et al. 2000, 2003). The mouths of nestlings are commonly colored by carotenoids (Hunt et al. 2003, Loiseau et al. 2008, Thorogood et al. 2008), pigments that can have positive effects on health (e.g. through antioxidant action or by aiding in immune function) independent of coloration (Lozano 1994, Olson and Owens 1998, von Schantz et al. 1999). Because of this trade-off between physiological and ornamental uses of these pigments, the carotenoid-content of tissue is widely hypothesized to signal quality (von Schantz et al. 1999, Møller et al. 2000), and seems to do so in at least some nestling birds (Saino et al. 2000, 2003, Loiseau et al. 2008). When parents respond to variation in these colors, they favor nestlings displaying carotenoid-rich mouth parts (Saino et al. 2000, Ewen et al. 2008, Loiseau et al. 2008, Dugas 2009).

Other potential explanations for the specialized features of the nestling mouth (presence of flanges and coloration) do not rest on the assumption that these traits play any role in visual communication. By bordering the mouth, flanges 

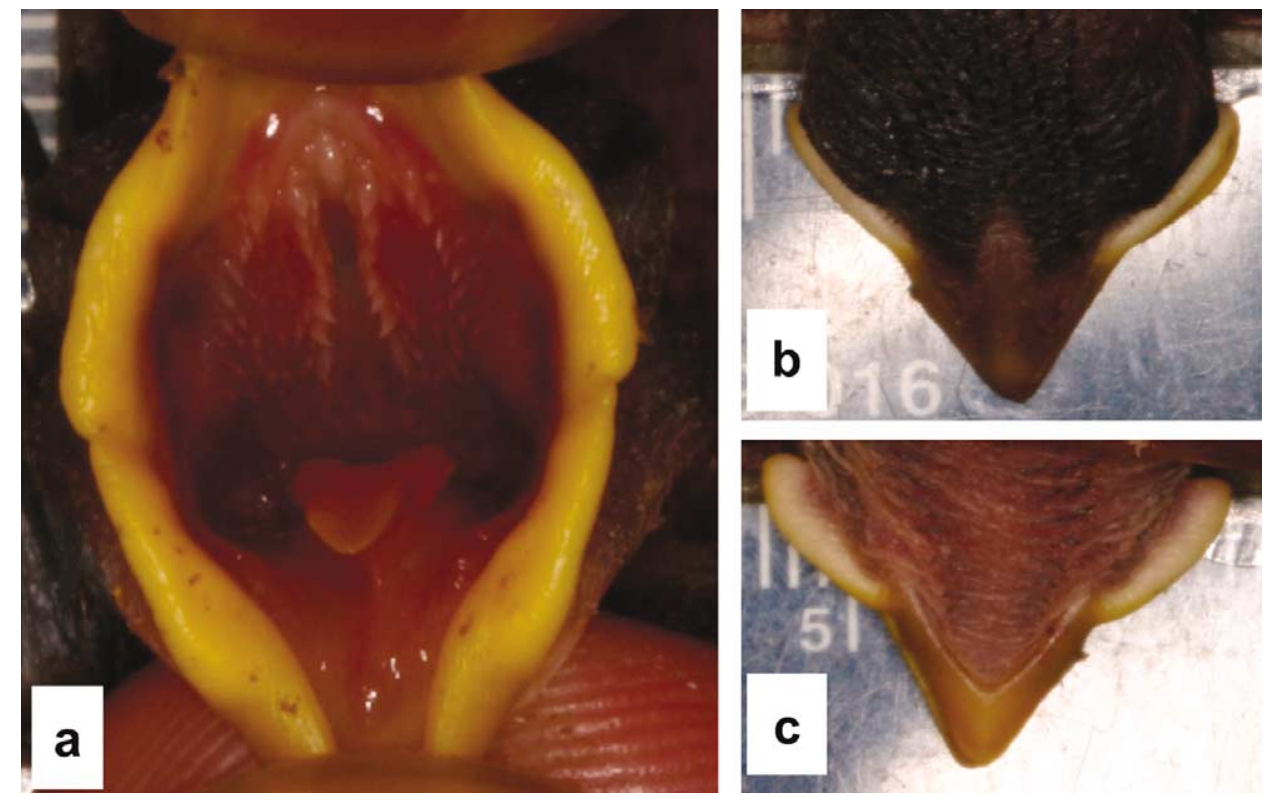

Figure 1. Photographs illustrating the portion of the rictal flange visible when a nestling house sparrow begs (a) and the dorsal (b) and ventral (c) surfaces of the flange that would not be visible during begging. All three photographs are of an individual nestling on the same day.

could create a funnel-like physical barrier to the loss of food from the underdeveloped nestling mouth (Dewar 1908). Dewar's (1908) observation that flanges are more highly developed in species with dark nests, where the transfer of food is presumably an error-prone task, has been confirmed by more recent comparative work (Kilner and Davies 1998). The coloration of mouth parts could also increase nestling fitness without acting as a visual signal. If carotenoids could be stored in mouth parts and then mobilized later, accumulation of these pigments could offer a fitness advantage without necessarily playing a role as a visual signal. Alternatively, carotenoids could accumulate in mouth tissue with no adaptive value at all, perhaps as an incidental result of the relatively carotenoid-rich insect diet (Olson 2006) upon which most passerine nestlings are reared. A parallel example would be the accumulation of pink carotenoids in the tissue of nestling white storks Ciconia ciconia after the introduction of an exotic crustacean to their diet (Negro et al. 2000).

If large and colorful flanges function primarily as a visual signal, then the surface of the flange tissue, conspicuous during begging, should have enhanced optical qualities relative to surfaces of this tissue not presented to parents during begging. To test this prediction, I compared two surfaces of flange tissue in nestlings of two passerine species, house sparrows Passer domesticus and cliff swallows Petrochelidon pyrrhonota. Rictal flanges are relatively flat structures that extend laterally from the bill and mouth, and thus have one surface exposed when the mouth is open (e.g. during gaping), and two other surfaces (on the dorsal and ventral surfaces of the bill) exposed when the mouth is closed (Fig. 1). I quantified standard color parameters associated with visual signals: 1) total brightness, likely associated with the visual conspicuousness of flanges, 2) chroma, an index of carotenoid content expected to be associated with signaling of quality, and 3) the intensity of ultraviolet (UV, 320-400 nm) coloration, which could be associated with both conspicuousness and signaling of quality. If flange colors function as visual signals, I specifically expected all three color parameters to be expressed more intensely in tissue exposed during begging.

\section{Methods}

\section{Study animals}

House sparrow nestlings were drawn from a nest box population in Norman, OK, USA. Nests were monitored regularly to determine day of hatching (day 0 ) and one chick per brood was sampled on days $3(\mathrm{n}=27), 6$ $(\mathrm{n}=29)$, and $9(\mathrm{n}=18)$. To ensure that no nestling was sampled at more than one age, the tarsi of nestlings were colored with non-toxic markers for individual identification. Cliff swallow nestlings were drawn from nesting colonies in Cleveland and Pottawatomie counties, OK, USA. Only one chick per cliff swallow nest was sampled, and each nest was used only once $(\mathrm{n}=14)$. Because cliff swallow colonies were not visited regularly, nestling age was unknown.

\section{Measurement and quantification of color}

Reflectance of the rictal flange tissue was measured with a USB4000 spectrometer fitted with a bifurcated reflectance probe (Ocean Optics, Dunedin, USA). Light produced by a deuterium-tungsten halogen lamp (Ocean Optics, DT-MINI-2-GS) illuminated an approximately $5 \mathrm{~mm}^{2}$ area of tissue, and the tissue's reflectance relative to white standard (WS-1) was recorded using Spectra Suite software (Ocean Optics). All color measurements were taken in the field using a portable dark box to exclude ambient light.

The reflectance of flange tissue visible to parents during begging was assessed by gently holding the mouth open, 
and the part not visible was measured while holding the mouth closed. The reflectance probe was placed at a 90 degree angle to the tissue (Andersson and Prager 2006). The flange can be intuitively divided into four quadrants: the right and left side of flange bordering the maxilla and mandible (Fig. 1). For each quadrant, one reflectance measurement was taken from the flange surface that would be visible during begging and one from the surface that would not be visible. The medians of these four measurements for each flange surface (visible vs not visible) were used for further analysis.

Reflectance measurements were recorded as percent reflectance at each wavelength, and all wavelengths relevant to avian vision (320-700 nm: Bleiweiss 2008) were included. These measurements were converted to three commonly used variables that describe the shape of a reflectance curve in ways relevant both to vision and the level of pigment deposition: 1) brightness (Endler 1990) captures total light reflected by a tissue (average reflectance 320-700 nm), 2) UV chroma (Andersson et al. 1998) quantifies the proportion of total reflectance that comes from UV-A wavelengths (320-400 nm), which are visible to most birds (Cuthill 2006), and 3) chroma (Endler 1990) measures the saturation of the curve (i.e. how different the maximum and minimum reflectances are). Because carotenoid-deposition colors tissues by absorbing short-wavelength light (i.e. blue and green), a comparison of reflectance at short and long wavelengths is commonly used to estimate the carotenoid content of tissues (reviewed by Montgomerie 2006). This particular saturation estimate (chroma sensu Endler 1990) has been shown to predict carotenoid pigment concentration in tissues (Saks et al. 2003) including flanges (M. B. Dugas and K. J. McGraw unpublished).

\section{Statistical analyses}

I compared the color of begging and non-begging flange tissue of individual nestlings with paired-t tests when difference scores were normally distributed and Wilcoxon signed-rank tests when they were not normally distributed. Each color parameter quantified here is expected to capture a visually-relevant property of tissue (Endler 1990). Although these parameters can be correlated (Andersson and Prager 2006), the final optical properties of the tissue were of interest here. Accordingly, I analyzed each color parameter separately (Montgomerie 2006).
Because nestling mouth color may also be associated with age (de Ayala et al. 2007, Loiseau et al. 2008), the extent to which any color differences between the two flange surfaces were different between ages was also of interest. In house sparrows, color parameter difference scores were compared at three post-hatching ages (day 3, $6,9)$ using repeated-measures ANOVAs (with only broods that had been sampled on all three days), and in cliff swallows, mass was used as a proxy for age and compared with difference scores using correlations.

\section{Results}

\section{House sparrows}

Mean reflectance of both flange tissues are presented in Fig. 2. Flange tissue visible to parents was brighter $(Z=$ $-2.61, \mathrm{n}=29, \mathrm{P}=0.009$ ), more UV-rich (paired $\mathrm{t}_{28}=$ 2.56, $\mathrm{P}=0.016$ ) and had higher chroma values (paired $\left.\mathrm{t}_{28}=10.63, \mathrm{P}<0.001\right)$ than the portion of the flange that would not be visible to parents at day 6 (Table 1), and these differences were also significant on days 3 and 9 (all $\mathrm{P}<0.018)$. The difference in brightness $\left(\mathrm{F}_{2,24}=0.38\right.$, $\mathrm{P}=0.687)$ and UV chroma $\left(\mathrm{F}_{2,24}=0.26, \mathrm{P}=0.773\right) \mathrm{did}$ not change to a demonstrable degree with nestling age. The difference in chroma between the flange visible to parents during begging and the portion not visible increased with age (mean $\pm S D$ : day $3=0.06 \pm 0.04$; day $6=0.09 \pm 0.05$; day $\left.9=0.12 \pm 0.04 ; \quad F_{2,24}=6.41, \quad P=0.006\right)$, although neither tissue portion changed with age when considered individually (visible tissue: $\mathrm{F}_{2,24}=2.83, \mathrm{P}=0.079$; hidden: $\left.\mathrm{F}_{2,24}=3.22, \mathrm{P}=0.058\right)$

\section{Cliff swallows}

Mean reflectance of both flange tissues are presented in Fig. 2. Flange tissue visible to parents was brighter (paired $\mathrm{t}_{13}=4.17, \mathrm{P}=0.001$ ), more UV-rich (paired $\mathrm{t}_{13}=2.81$, $\mathrm{P}=0.015$ ), and had higher chroma values (paired $\mathrm{t}_{13}=$ 2.67, $\mathrm{P}=0.019)$ than the portion of the flange not visible to parents (Table 1). Neither the difference in brightness $(\mathrm{r}=-0.277, \mathrm{n}=14, \mathrm{P}=0.338)$, nor $\mathrm{UV}$ chroma $(\mathrm{r}=0.260, \mathrm{n}=14, \mathrm{P}=0.369)$ were associated with nestling mass, while the chroma difference of exposed and hidden tissue was greater in larger nestlings $(r=0.673$,

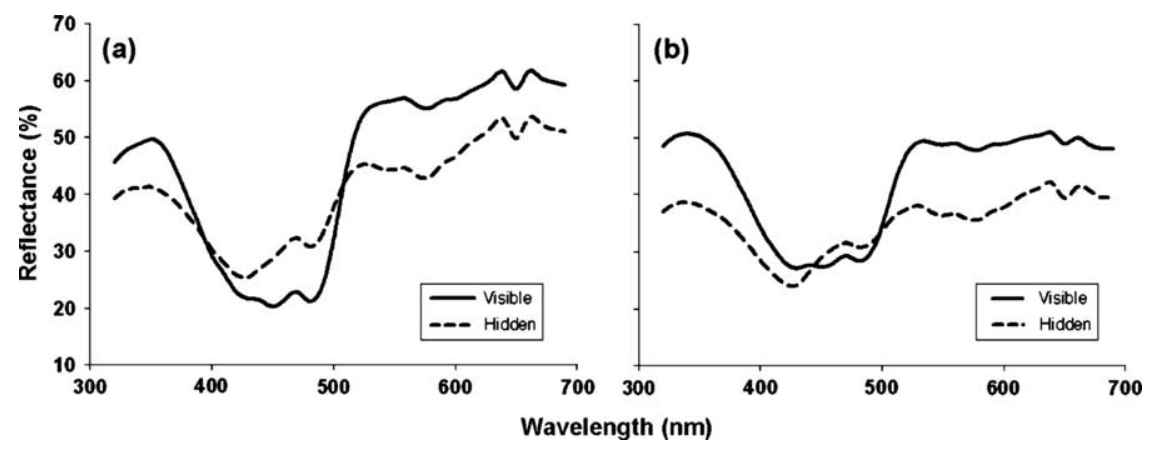

Figure 2. Reflectance of flange tissue that visible to parents during nestling begging (solid lines) and tissue that would be hidden during begging (dashed lines) in nestling house sparrows at day 6 (a) and in nestling cliff swallows (b). 
Table 1. Mean $( \pm 1 \mathrm{SD})$ of color variables from the portion of the flange visible to parents during begging, the portion hidden, and the difference between the two (visible-hidden) in house sparrow (day 6) and cliff swallow nestlings. Brightness and UV chroma are expressed as proportions. While chroma has no specific units, a completely flat reflectance curve would have a chroma value of 0 and higher values represent a more saturated color (Endler 1990).

\begin{tabular}{lccc}
\hline House sparrows: & Visible tissue & Hidden tissue & Difference (visible-hidden) \\
\cline { 2 - 4 } Brightness & $0.45 \pm 0.06$ & $0.40 \pm 0.07$ & $0.05 \pm 0.08$ \\
UV chroma & $0.21 \pm 0.01$ & $0.20 \pm 0.02$ & $0.01 \pm 0.02$ \\
Chroma & $0.23 \pm 0.04$ & $0.13 \pm 0.04$ & $0.09 \pm 0.05$ \\
Cliff swallows: & Visible tissue & Hidden tissue & Difference (visible-hidden) \\
Brightness & $0.43 \pm 0.05$ & $0.36 \pm 0.06$ & $0.08 \pm 0.06$ \\
UV chroma & $0.23 \pm 0.02$ & $0.22 \pm 0.02$ & $0.01 \pm 0.01$ \\
Chroma & $0.14 \pm 0.06$ & $0.10 \pm 0.04$ & $0.03 \pm 0.06$ \\
\hline
\end{tabular}

$\mathrm{n}=14, \mathrm{P}=0.008)$. The chroma of both flange surfaces was positively associated with mass, although the relationship was significant only for tissue visible to parents (visible tissue: $\mathrm{r}=0.849, \mathrm{n}=14, \mathrm{P}<0.001$; hidden tissue: $\mathrm{r}=0.496, \mathrm{n}=14, \mathrm{P}=0.071$ ).

\section{Discussion}

In both species, flange tissue displayed to parents during begging was brighter and more UV- and carotenoid-rich than the tissue not exposed. Between-tissue differences in brightness and UV-richness were consistent across ages, while the visible tissue became relatively more chromatic in older chicks. While specialization of the flange surface displayed during begging certainly does not exclude the possibility that flanges also increase nestling fitness through non-signaling means (e.g. by acting as a physical border to the palate or a storage site for carotenoids), it is consistent with the hypothesis that this trait functions as a visual signal and that flange coloration has evolved in this context. Flanges could have evolved a signaling role secondarily if, for example, carotenoids were passively accumulated in flange tissue and these novel colors exploited or at least built upon a parental preference for food colored by carotenoids (Kilner 1999). Future comparative work would be particularly useful for understanding whether these colors evolved only in the signaling tissue or if they were secondarily lost from the non-signaling tissue.

The ways in which the tissue visible during begging is specialized are consistent with two major hypotheses, increased conspicuousness and signaling of quality, that explain the visual signaling role of flange colors. The portion of the flange visible to parents during begging is probably more detectable than the portion hidden would be if displayed. The overall brightness of tissue is positively associated with the visual conspicuousness (Osorio et al. 1999) and because nesting material is relatively poor in UV reflectance, flange UV reflectance has also been hypothesized to increase chick conspicuousness in cavity nests (Hunt et al. 2003). By displaying conspicuous colors only while gaping, nestlings may also minimize risk from visually-oriented predators. Further work comparing nestlings from visually risky nests to those from visually protected nests (like those studied here) may shed light on the importance of this selective pressure.

Both the UV- and carotenoid-based coloration of flanges are expressed more intensely in tissue displayed during begging, and both may provide parents with information about offspring condition. UV reflectance of nestling skin is, in some species, associated with immune function (Jourdie et al. 2004, Soler et al. 2007) or mass (Bize et al. 2006), although the UV reflectance of flanges specifically has not been shown to be associated with nestling condition (Jourdie et al. 2004, Bize et al. 2006, de Ayala et al. 2007). The carotenoid-content of flange tissue is associated with nestling quality in house sparrows (Loiseau et al. 2008) and barn swallows Hirundo rustica (Saino et al. 2000, 2003), a close relative of the cliff swallows studied here. By allocating carotenoids or UV-reflecting microstructures (Prum and Torres 2003) only to tissues directly involved in signaling, nestlings may minimize the cost of signal production. The pigmentation of individual bird feathers mirrors the pattern of flange pigmentation: within individual feathers, regions hidden from potential receivers are often unpigmented, while the feather parts contributing to a visual signal are elaborately colored (Newbigin 1898, Mays et al. 2004).

That brightness, UV chroma and carotenoid-based chroma are all expressed more intensely in the flange tissue used in begging is surprising given how carotenoids influence color. Carotenoids create yellows, oranges and reds by absorbing short-wavelengths, and to a lesser extent, UV light (Andersson and Prager 2006, Bleiweiss 2008), and so the reflectance of a tissue is a result of both carotenoids and underlying structural colors (Shawkey and Hill 2005). If both surfaces were otherwise identical, the more carotenoid-rich tissue of the visible flange should be less bright and less UV-rich than the carotenoid-poor hidden tissue (Thorogood et al. 2008). That the opposite is true suggests that specialized structural features of the flange increase its brightness and UV reflectance. The conserved influences of carotenoids have been hypothesized to limit the visual conspicuousness of carotenoid-based colors, especially when light conditions are limiting (Andersson 2000, Dugas and Rosenthal 2010), and to constrain the possible combinations of long and short wavelength reflectance in tissues colored by carotenoids (Bleiweiss 2008). However, analysis of feathers (Mays et al. 2004) and now 
flange tissue suggest that birds can evolve mechanisms to at least partially overcome these constraints.

Acknowledgements - J. Place assisted with fieldwork, and T. Gibbons developed a program to process spectrometer files. M. Tobler, S. Strickler, D. Mock, P. L. Schwagmeyer, I. Schlupp, the ZEEB Graduate Review provided comments that greatly improved the quality of this manuscript. This research was funded with a George Miksch Sutton Scholarship in Ornithology. The Univ. of Oklahoma IACUC (RM6-012) approved all protocols, and permits were granted by the Oklahoma Wildlife Conservation Dept.

\section{References}

Andersson, S. 2000. Efficacy and content in avian colour signals. - In: Espmark, Y., Amundsen, T. and Rosenqvist, G. (eds). Animal signals: signalling and signal design in animal communication. Tapir Academic, pp. 47-60.

Andersson, S. and Prager, M. 2006. Quantifying colors. - In: Hill, G. E. and McGraw, K. J. (eds). Bird coloration. Vol. 1. Mechanisms and measurements. Harvard Univ. Press, pp. 41-89.

Andersson, S., Örnborg, J. and Andersson, H. 1998. Ultraviolet sexual dimorphism and assortative mating in blue tits. - Proc. R. Soc. B 265: 445-450.

Avilés, J. M., Peréz-Contreras, T., Navarro, C. and Soler, J. J. 2008. Dark nests and conspicuousness in color patterns of nestlings of altricial birds. - Am. Nat. 171: 327-338.

Bell, M. B. V. 2007. Cooperative begging in banded mongoose pups. - Curr. Biol. 17: 717-721.

Bize, P., Piault, R., Moureau, B. and Heeb, P. 2006. A UV signal of offspring condition mediates context-dependent parental favouritism. - Proc. R. Soc. B 273: 2063-2068.

Bleiweiss, R. 2008. Phenotypic integration expressed by carotenoid-bearing plumages of tanager finches (Thraupini, Emberizinae) across the avian visible spectrum. - Biol. J. Linn. Soc. 93: 89-109.

Clark, G. A. Jr. 1969. Oral flanges of juvenile birds. - Wilson Bull. 81: 270-279.

Clotfelter, E. D., Schubert, K. A., Nolan, V. Jr. and Ketterson, E. D. 2003. Mouth color signals thermal state of nestling dark-eyed juncos. - Ethology 109: 171-182.

Clutton-Brock, T. 1991. The evolution of parental care. - Princeton Univ. Press.

Cuthill, I. C. 2006. Color perception. - In: Hill, G. E. and McGraw, K. J. (eds). Bird coloration. Vol. 1. Mechanisms and measurements. Harvard Univ. Press, pp. 41-89.

de Ayala, R. M., Saino, N., Møller, A. P. and Anselmi, C. 2007. Mouth coloration of nestlings covaries with offspring quality and influences parental feeding behavior. - Behav. Ecol. 18: 526-534.

den Boer, S. P. A. and Duchateau, M. J. H. M. 2006. A larval hunger signal in the bumblebee Bombus terrestris. - Insect Soc. 53: 369-373.

Dewar, J. M. 1908. The flanges and mouth-spots of nestlings. - Brit. Birds 1: 258-259.

Dugas, M. B. 2009. House sparrow (Passer domesticus) parents preferentially feed nestlings with mouth colours that appear carotenoid-rich. - Anim. Behav. 78: 767-772.

Dugas, M. B. and Rosenthal, G. G. 2010. Carotenoid-rich mouth colors influence the conspicuousness of nestling birds. - Behav. Ecol. Sociobiol. 64: 455-462.

Endler, J. A. 1990. On the measurement and classification of color in studies of animal color patterns. - Biol. J. Linn. Soc. 41: 315-352.
Ewen, J. G., Thorogood, R., Karadas, F. and Cassey, P. 2008. Condition dependence of nestling mouth colour and the effect of supplementing carotenoids on parental behaviour in the hihi (Notiomystis cincta). - Oecologia 157: 361-368.

Ficken, M. S. 1965. Mouth color of nesling passerines and its use in taxonomy. - Wilson Bull. 77: 71-75.

Galván, I., Ama, L. and Sanz, J. J. 2008. Ultraviolet-blue reflectance of some nestling plumage patches mediates parental favouritism in great tits Parus major. - J. Avian Biol. 39: 277-282.

Hunt, S., Kilner, R. M., Langmore, N. E. and Bennett, A. T. D. 2003. Conspicuous, ultraviolet-rich mouth colours in begging chicks. - Proc. R. Soc. B 270: S25-S28.

Ingram, C. 1920. A contribution to the study of nestling birds. - Ibis 2: 856-880.

Jourdie, V., Moureau, B., Bennett, A. T. D. and Heeb, P. 2004. Ultraviolet reflectance by the skin of nestlings. - Nature 431: 262.

Kaptein, N., Billen, J. and Gobin, B. 2005. Larval begging for food enhances reproductive options in the ponerine ant Gnamptogenys striatula. - Anim. Behav. 69: 293-299.

Kilner, R. 1997. Mouth color is a reliable signal of need in begging canary nestlings. - Proc. R. Soc. B 264: 964-968.

Kilner, R. M. 1999. Family conflicts and the evolution of nestling mouth colour. - Behaviour 136: 779-804.

Kilner, R. and Davies, N. B. 1998. Nestling mouth colour: ecological correlates of a begging signal. - Anim. Behav. 56: 705-712.

Loiseau, C., Fellous, S., Haussy, C., Chastel, O. and Sorci, G. 2008. Condition-dependent effects of corticosterone on a carotenoid-based begging signal in house sparrows. - Horm. Behav. 53: 266-273.

Lozano, G. A. 1994. Carotenoids, parasites, and sexual selection. - Oikos 70: 309-311.

Lyon, B. E., Eadie, J. M. and Hamilton, L. D. 1994. Parental favoritism selects for ornamental plumage in American coot chicks. - Nature 371: 240-243.

Mays, H. L., McGraw, K. J., Ritchison, G., Cooper, S., Rush, V. and Parker, R. S. 2004. Sexual dichromatism in the yellowbreasted chat Icteria virens: spectrophotometric analysis and biochemical basis. - J. Avian Biol. 35: 125-134.

Møller, A. P., Biard, C., Blount, J. D., Houston, D. C., Ninni, P., Saino, N. and Surai, P. F. 2000. Carotenoid-dependent signals: indicators of foraging efficiency, immunocompetence, or detoxification ability? - Avian Poultry Biol. Rev. 11: 137-159.

Montgomerie, R. 2006. Analyzing colors: in bird coloration. - In: Hill, G. E. and McGraw, K. J. (eds). Bird coloration. Vol. 1. Mechanisms and measurements. Harvard Univ. Press, pp. 90-147.

Negro, J. J., Tella, J. L., Blanco, G., Forero, M. G. and GarridoFernández, J. 2000. Diet explains interpopulation variation of plasma carotenoids and skin pigmentation in nestling white storks. - Physiol. Biochem. Zool. 73: 97-101.

Newbigin, M. I. 1898. Colour in nature: a study in biology. - John Murray.

Olson, V. A. 2006. Estimating nutrient intake in comparative studies of animals: an example using dietary carotenoids in birds. - Oikos 112: 620-628.

Olson, V. A. and Owens, I. P. F. 1998. Costly sexual signals: are carotenoids rare, risky or required? - Trends Ecol. Evol. 13: $510-514$

Osorio, D., Miklosi, A. and Gonda, Z. 1999. Visual ecology and perception of coloration patterns by domestic chicks. - Evol. Ecol. 13: 673-689.

Prum, R. O. and Torres, R. 2003. Structural colouration of avian skin: convergent evolution of coherently scattering dermal collagen arrays. - J. Exp. Biol. 206: 2409-2429. 
Saino, N., Ninni, P., Calza, S., Martinelli, R., de Bernardi, F. and Møller, A. P. 2000. Better red than dead: carotenoids-based mouth colouration reveals infection in barn swallow nestlings. - Proc. R. Soc. B 267: 57-61.

Saino, N., Ambrosini, R., Martinelli, R., Ninni, P. and Møller, A. P. 2003. Gape coloration reliably reflects immunocompetence of barn swallow (Hirundo rustica) nestlings. - Behav. Ecol. 14: 16-22.

Saks, L., McGraw, K. J. and Horak, P. 2003. How feather colour reflects its carotenoid content. - Funct. Ecol. 17: 555-561.

Shawkey, M. D. and Hill, G. E. 2005. Carotenoids need structural colours to shine. - Biol. Lett. 1: 121-124.

Soler, J. J., Avilés, J. M., Cuervo, J. J. and Perez-Contreras, T. 2007. Is the relationship between colour and immune response mediated by nutritional condition in spotless starling nestlings? - Anim. Behav. 74: 1139-1145.

Swynnerton, C. F. M. 1916. On the coloration of the mouths and eggs of birds. I: The mouths of birds. - Ibis 4: 264-294.

Thorogood, R., Kilner, R. M., Karadas, F. and Ewen, J. G. 2008. Spectral mouth colour of nestlings changes with carotenoid availability. - Funct. Ecol. 22: 1044-1051.

von Schantz, T., Bensch, S., Grahn, M., Hasselquist, D. and Wittzell, H. 1999. Good genes, oxidative stress and conditiondependent signals. - Proc. R. Soc. Lond. B 266: 1-12.

Wright, J. and Leonard, M. (eds) 2002. The evolution of begging. - Kluwer. 